\title{
QUALITY ASSESSMENT OF THE HOMOGENEOUS COORDINATE TIME SERIES OF EASTERN EUROPEAN GNSS STATIONS IN THE IGSO5 REFERENCE FRAME
}

\author{
M. Ishchenko \\ Main Astronomical Observatory of the National Academy of Sciences of Ukraine \\ Department of Space Geodynamics \\ Ukraine, 03680, Kiev, Akademika Zabolotnogo, 27 \\ e-mail:marina@mao.kiev.ua
}

\begin{abstract}
For the first time, a homogeneous coordinate solution in the IGS05 reference frame and the values of the zenith tropospheric refraction for the GPS weeks 935-1399 (from December 12, 1997 to November 4, 2006) were obtained at the GNSS Data Center Analysis of the Main Astronomical Observatory NAS of Ukraine.

The obtained solution is devoid of effects, brought by changes in the methods of processing models, a priori data and software (absolute phase center model combinations of antenna-dome instead of relative models, model of ocean loading FES2004 instead of GOT00.2_PP, the elevations cut-off angle $3^{\circ}$ instead of $10^{\circ}$, etc. were used).

To estimate the quality of the solution, a comparison with the international combined solutions using the Helmert transformation was carried out. The RMS of direct station coordinate differences and correlation coefficients between the solutions estimated by the Main Astronomical Observatory, European GNSS Permanent Network and International GNSS Service are presented.

The obtained results allow making the conclusion that the solution obtained at the GNSS Data Center Analysis of the Main Astronomical Observatory shows a good quality and agrees well with other solutions.
\end{abstract}

Keywords: reprocessing of GPS observations, homogeneous coordinates time series, zenith tropospheric refraction, Global Positioning System. 


\section{INTRODUCTION}

At the GNSS Data Center Analysis of the Main Astronomical Observatory NAS of Ukraine, observations of GPS satellites for GPS weeks 935-1399 (December 7, 1997 - November 4, 2006) were reprocessed. The reprocessing was carried out for the 31 GPS stations in the IGS05 reference frame, which are located in Eastern Europe.

Bernese GPS Software ver. 5.0 [1], developed at the Astronomical Institute of the University of Bern, Switzerland, was used for the reprocessing of GPS observations along with the recommendations of the Central Bureau of European GNSS permanent network, which came into effect from GPS week 1400 [3] for the processing.

To perform the preprocessing, satellite 30-s observations files in the RINEX format were used. In the reprocessing, improved GPS orbits and Earth rotation parameters are used, which were obtained as a result of reprocessing associated with the improvement of the GPS satellite orbits [10]. The absolute model antenna phase center variations were taken from the ANTEX file. The ocean tidal loading displacements for GPS stations were calculated on the basis of the model FES2004 [4]. The Earth gravity field model JGM3 and ephemeris of the Sun and the Moon DE2000 [8], provided the Jet Propulsion Laboratory, JPL NASA, were used. The a priori coordinates and velocities of stations were taken from the IGS05 catalogue with a reference to the epoch 2000.0. To define the coordinate system, the minimum constraint condition No-NetTranslation on the coordinates of stations GLSV, POLV, MDVJ, BOR1, TRAB, MATE and WTZR was applied. A priori model Saastamoinen [7], defined by option DRY_NIELL [6], for modeling of zenith tropospheric refraction was used. The tropospheric gradient TILTING [1] for satellites with low elevation angles was used. The Quasi ionosphere free algorithm [1] to fix the phase ambiguities and the global model of the ionosphere on each day, presented by CODE, was used. The nutation and precession model IAU2000 [5] was taken into account, as well.

The process of obtaining solution for the separate GPS week can be divided into several stages: preprocessing of daily sessions of observations; obtaining estimates of coordinates for the every day of observations; estimating of station coordinates for the whole GPS week; obtaining the final tropospheric zenith path delay parameters for each station.

As a result of processing of archival GPS observations at the GNSS Data Center Analysis, the homogeneous coordinate time series and tropospheric zenith path delay parameters for the 464 GPS weeks were obtained [2]. Solution MAO Reprol labeled as MA1 and available at MAO ftpserver (ftp://ftp.mao.kiev.ua/pub/gnss/products/IGS05/).

To estimate the quality of the resulting solution $M A 1$, comparisons with the combined reprocessing solutions EPN Repro1 [11-12], performed by European GNSS Permanent Network, and IGB Reprol [4] performed by International GNSS Service are presented.

The locations of the GPS stations, which were used to compare three solutions, are shown in the fig. 1. The list of the GPS stations with additional information is presented in the table 1 (see appendix). 


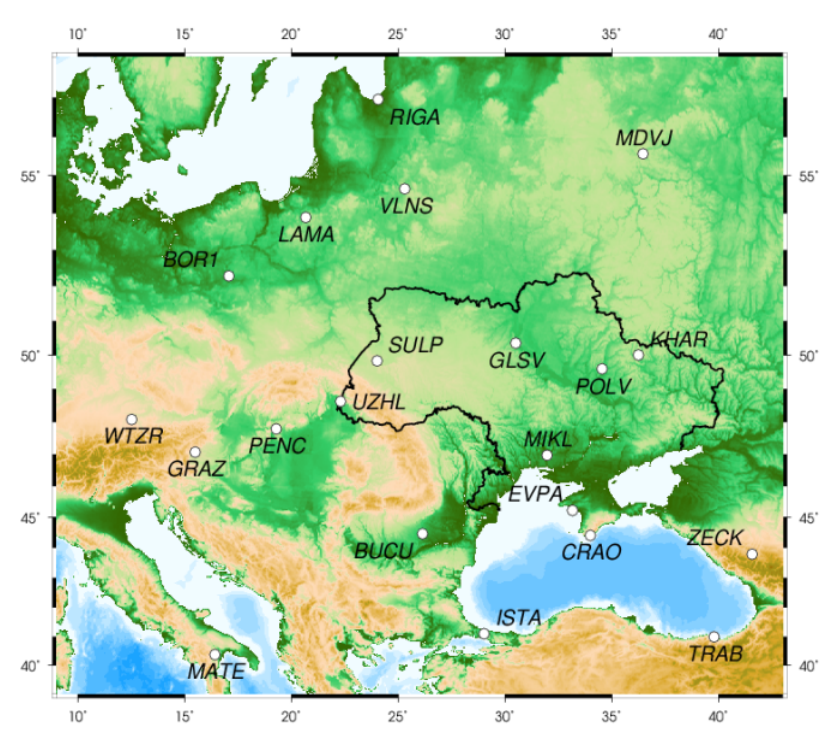

Fig. 1. Location of the GPS stations in Eastern Europe

\section{COMPARISON OF THE SOLUTION MAO REPRO1 WITH A COMBINED SOLUTION EPN REPRO1}

In 2010, the Working Group of the European GNSS Permanent Network (EPN), i.e., the regional GNSS densification network in Europe, decided to start reprocessing campaign for EPN GPS stations. The processing was carried out in the accordance with the EPN guidelines and geographic location.

EPN began a campaign, called as EPN Repro1, in which archival GPS observations were processed. The results of the reprocessing campaign EPN Reprol are available at ftp-server EPN (ftp://igs.bkg.bund.de/EPNrepro1/products/) [11-12]. Solution was labeled as EUO.

Having combined EPN solution made it possible to perform an evaluation of the quality of the reprocessing MAO Reprol obtained at the Center for Analysis of GNSS data.

To verify the quality of the solution, the Helmert transformation parameters between the solution $M A 1$ and the combined solution EUO were obtained for stations which are present in both solutions. Minimum and maximum values lie in the following ranges:

\section{Translation:}

axis $X$ : from $-21.2 \mathrm{~mm}$ to $18.3 \mathrm{~mm}$,

axis $Y$ : from $-45.2 \mathrm{~mm}$ to $36.9 \mathrm{~mm}$,

axis $Z$ : from $-23.4 \mathrm{~mm}$ to $18.8 \mathrm{~mm}$.

Mean values:

axis $X:-0.5 \mathrm{~mm}$,

axis $Y: 6.2 \mathrm{~mm}$,

axis $Z: 0.6 \mathrm{~mm}$.

Rotation:

around the axis $X$ : from $-0.99 \mathrm{~ms}$ arc to $0.78 \mathrm{~ms}$ arc, around the axis $Y$ : from $-0.72 \mathrm{~ms}$ arc to $0.87 \mathrm{~ms}$ arc, around the axis $Z$ : from $-0.80 \mathrm{~ms}$ arc to $0.84 \mathrm{~ms}$ arc. 
Mean values:

around the axis $X:-0.12$ mas,

around the axis $Y:-0.03$ mas,

around the axis $Z: 0.10$ mas.

Scale factor:

from $-1,6 \cdot 10^{-9}$ to $0,9 \cdot 10^{-9}$.

Mean value:

$-0.3 \cdot 10^{-9}$

Fig. 2 shows the mean residual values for the coordinates of permanent stations after the Helmert transformation between solutions $M A 1$ and $E U O$ for stations in two solutions.

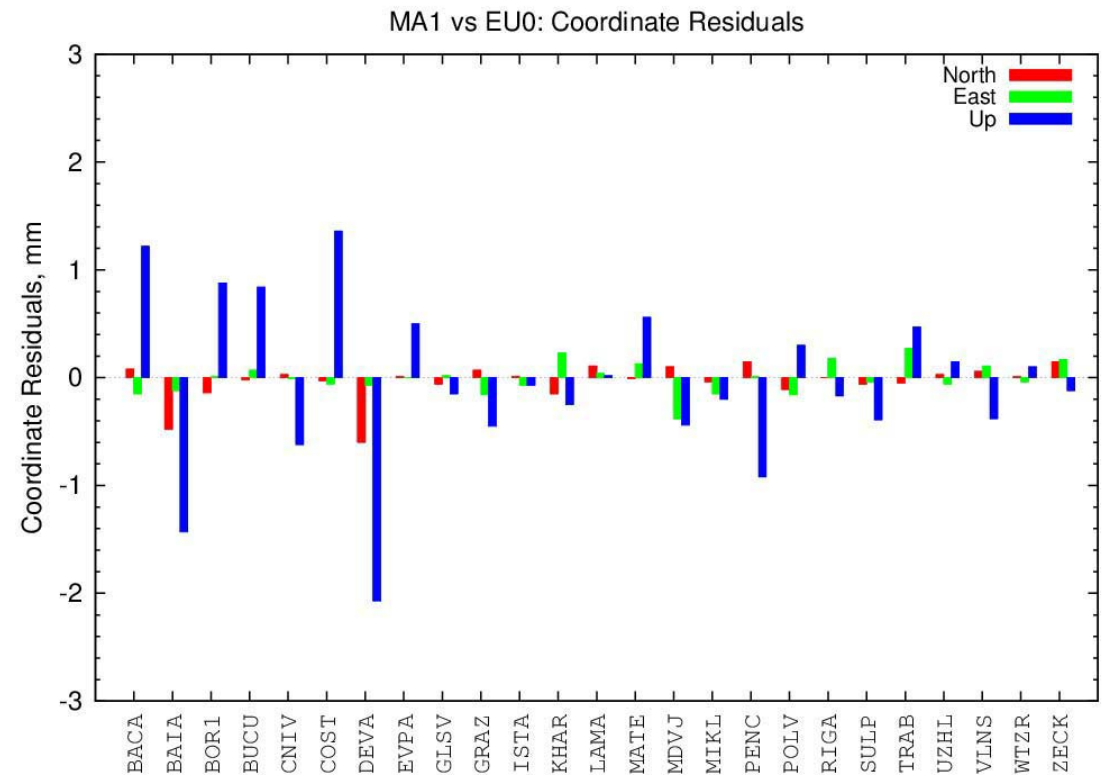

Fig. 2. The mean residual values for the coordinates after the Helmert transformation between solutions $M A 1$ and EUO

Lowest and highest mean residual module consists of the following values:

from $0.00 \mathrm{~mm}$ (station RIGA) to $0.60 \mathrm{~mm}$ (station DEVA) for the north component,

from $0.00 \mathrm{~mm}$ (station DEVA) to $0.38 \mathrm{~mm}$ (station MDVJ) for the east component,

from $0.01 \mathrm{~mm}$ (station MIKL) to $2.07 \mathrm{~mm}$ (station DEVA) for the up component.

The resulting non-zero residuals coordinate transformations after Helmert are explained with different way of coordinate system realization (different geometry of networks and a different set of reference stations).

Fig. 3 shows the mean values of the zenith tropospheric refraction differences between solutions MAI and EUO. 


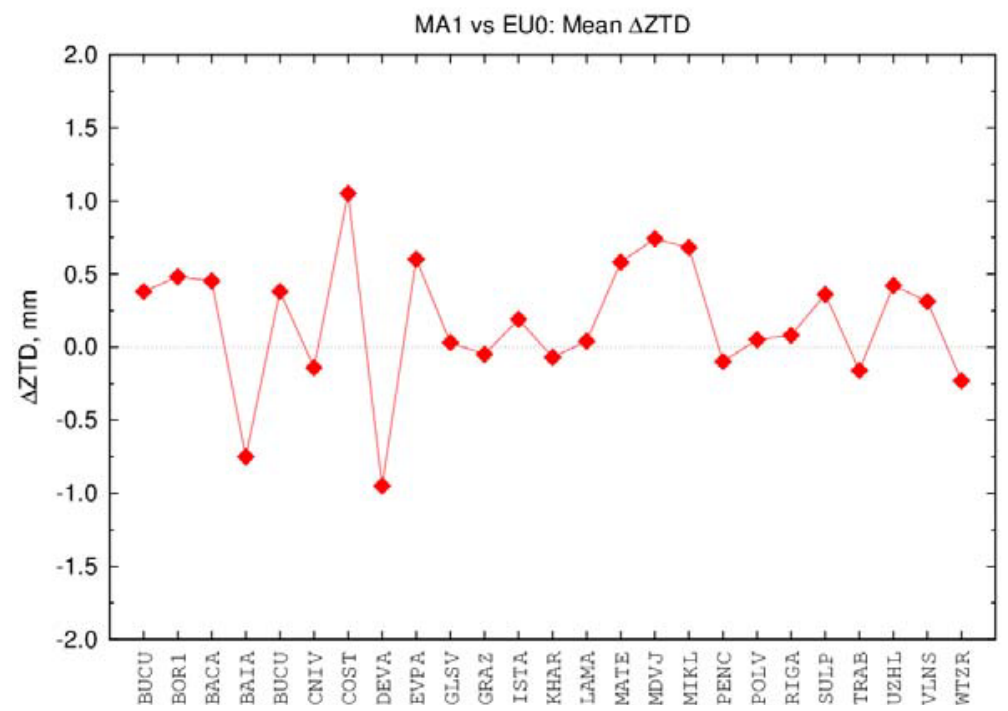

Fig. 3. The mean values of the zenith tropospheric refraction differences between solutions $M A 1$ and $E U O$

Using tropospheric gradient allows taking into account observations from the GPS satellites observed at low elevations, leading to improved estimates of the zenith tropospheric refraction parameters. Average values of the zenith tropospheric refraction differences lie within the limits (from $-0.95 \mathrm{~mm}$ DEVA to $1.05 \mathrm{~mm}$ COST).

One way of quality assessments is a comparison of the coordinate repeatability for the MAI and $E U 0$ solutions. It has been revealed that the repeatability of the coordinates for both solutions are very similar (see the fig. 4).

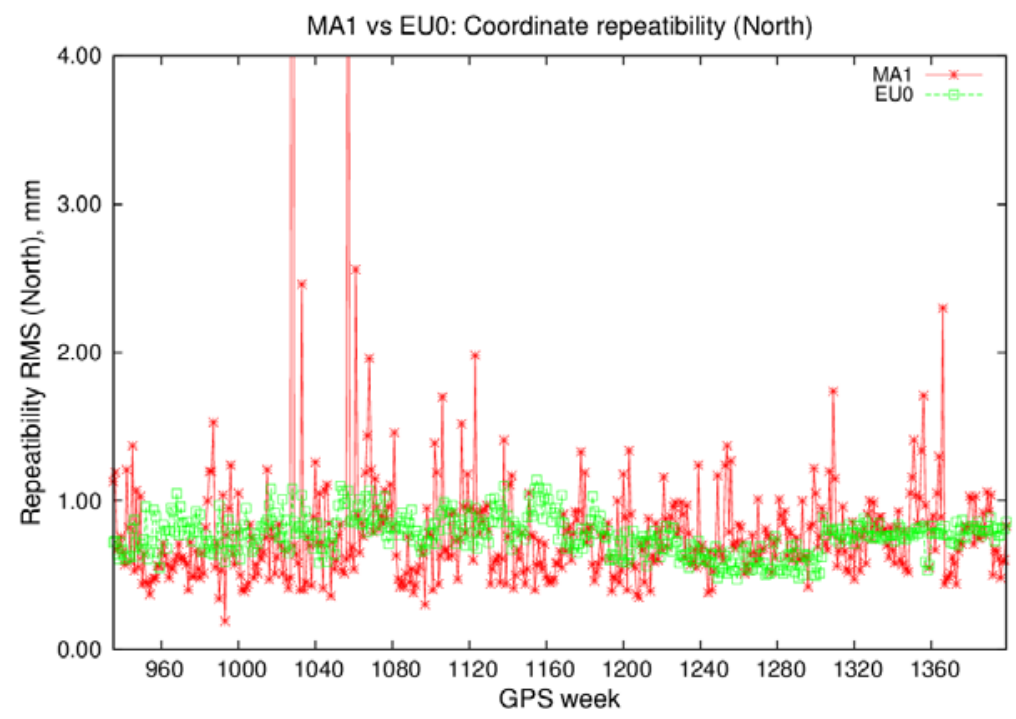

a

Fig. 4 (part a). Coordinate repeatability from the solutions $M A 1$ and $E U O$ (a - north, b east, c - up components) 


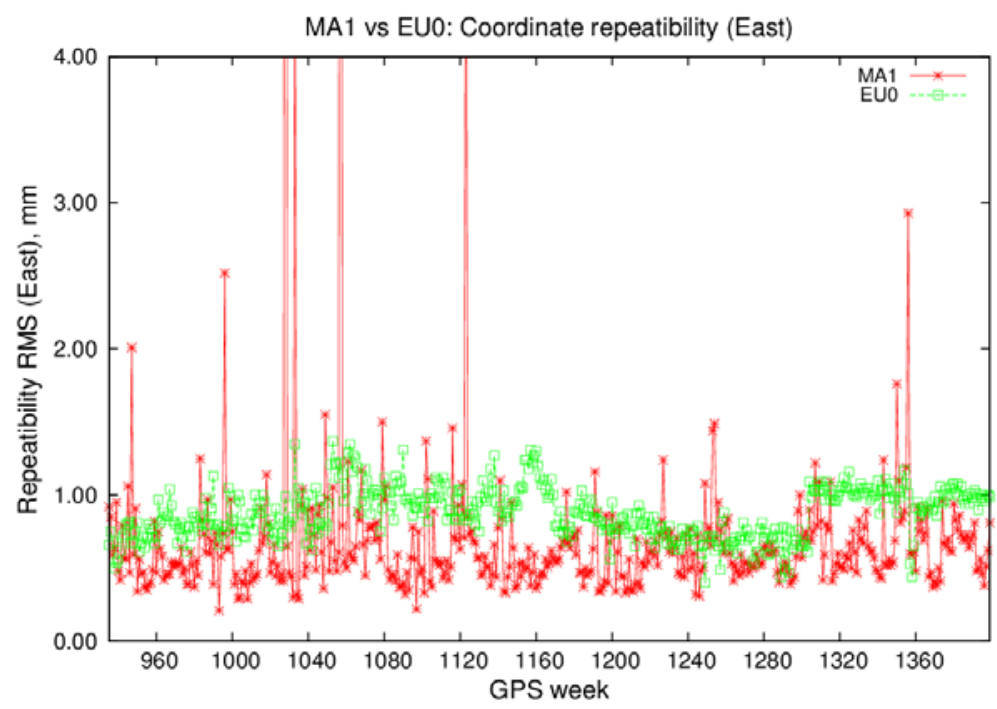

$\mathrm{b}$

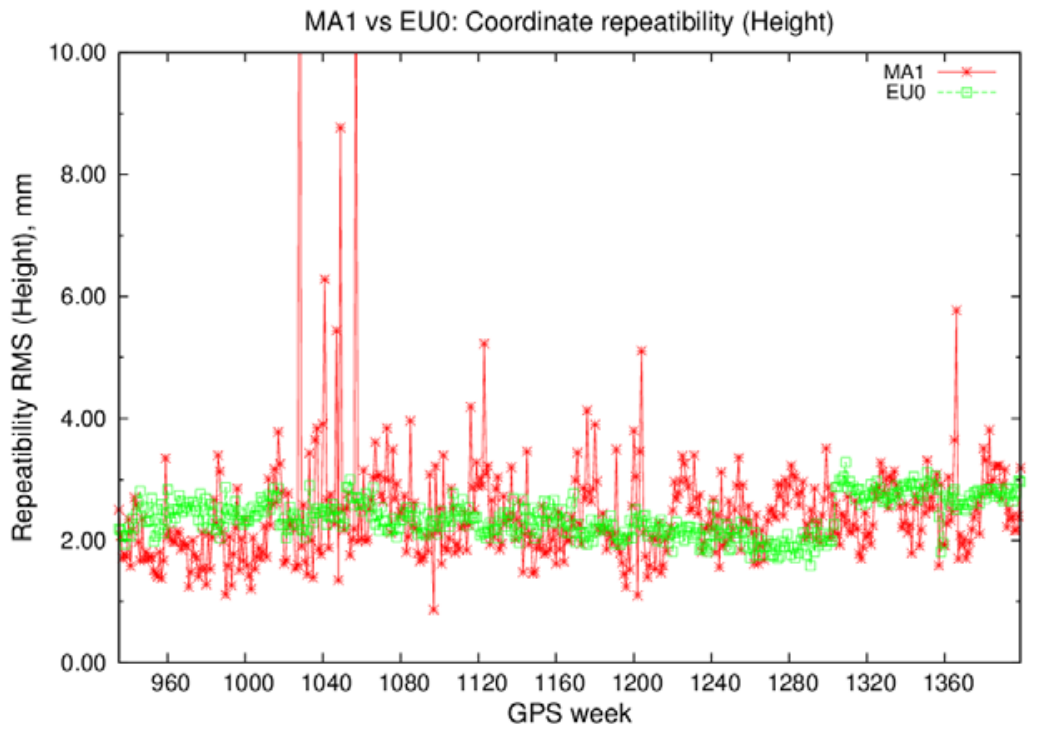

$\mathrm{c}$

Fig. 4 (parts b and c). Coordinate repeatability from the solutions $M A 1$ and $E U O$ (a north, $\mathrm{b}$ - east, $\mathrm{c}$ - up components)

Mean values of the coordinate repeatability for $M A 1$ and EUO solutions are as follows:

$0.8 \mathrm{~mm}$ and $0.8 \mathrm{~mm}$ for the north component,

$0.7 \mathrm{~mm}$ and $0.9 \mathrm{~mm}$ for the east component,

$2.2 \mathrm{~mm}$ and $2.4 \mathrm{~mm}$ for the up component, respectively.

As one can see from the values above, coordinate repeatability for both solutions is almost at the same level. Based on the foregoing, the quality of the resulting reprocessing solution MAI coincides with the combined solution of EPN. 


\section{COMPARISON RESULTS OF THE SOLUTION MAO REPRO1 WITH THE COMBINED SOLUTION IGS REPROI}

International GNSS Service (IGS) initiated a reprocessing campaign called as IGS Reprol. Improved GPS orbits and Earth rotation parameters were used in the reprocessing, which were obtained as a result of the reprocessing, associated with the improvement of the GPS satellite orbits [10]. As a result of the reprocessing, the consistent time series of station coordinates were obtained. SINEX files of the solution IGS Reprol available at the $\mathrm{ftp}$-server IGS (ftp://igsrf.ensg.eu/pub/igb/) [9]. Solution is hereinafter labeled as $I G B$.

The existence of combined EPN solution makes it possible to perform an evaluation of the quality of the results with respect to the reprocessing MAO Reprol from the Center for Analysis of GNSS data.

To verify a quality of the solution, the Helmert transformation parameters between the solution $M A 1$ and the combined solution $I G B$ were obtained for the stations which are present in both solutions. Minimum and maximum obtained values lie in the following ranges:

\section{Translation:}

axis $X$ : from $-14.0 \mathrm{~mm}$ to $24.2 \mathrm{~mm}$,

axis $Y$ : from $-8.3 \mathrm{~mm}$ to $26.7 \mathrm{~mm}$,

axis $Z$ : from $-5.1 \mathrm{~mm}$ to $29.7 \mathrm{~mm}$.

Mean values:

axis $X: 7.5 \mathrm{~mm}$,

axis $Y: 8.3 \mathrm{~mm}$,

axis $Z: 12.0 \mathrm{~mm}$.

Rotation:

around axis $X$ : from -0.61 mas to 0.49 mas,

around axis $Y$ : from -0.61 mas to 0.47 mas,

around axis $Z$ : from -0.33 mas to 0.50 mas.

Mean values:

around axis $X:-0.31$ mas,

around axis $Y: 0.05$ mas,

around axis $Z$ : 0.04 mas.

Scale factor:

from $-3,3 \cdot 10^{-9}$ to $-1,7 \cdot 10^{-9}$.

Mean value:

$-2.4 \cdot 10^{-9}$

Fig. 5 shows the mean residual values after the Helmert transformation between solutions $M A I$ and $I G B$ for the coordinates of permanent GPS stations that are present in both solutions. 


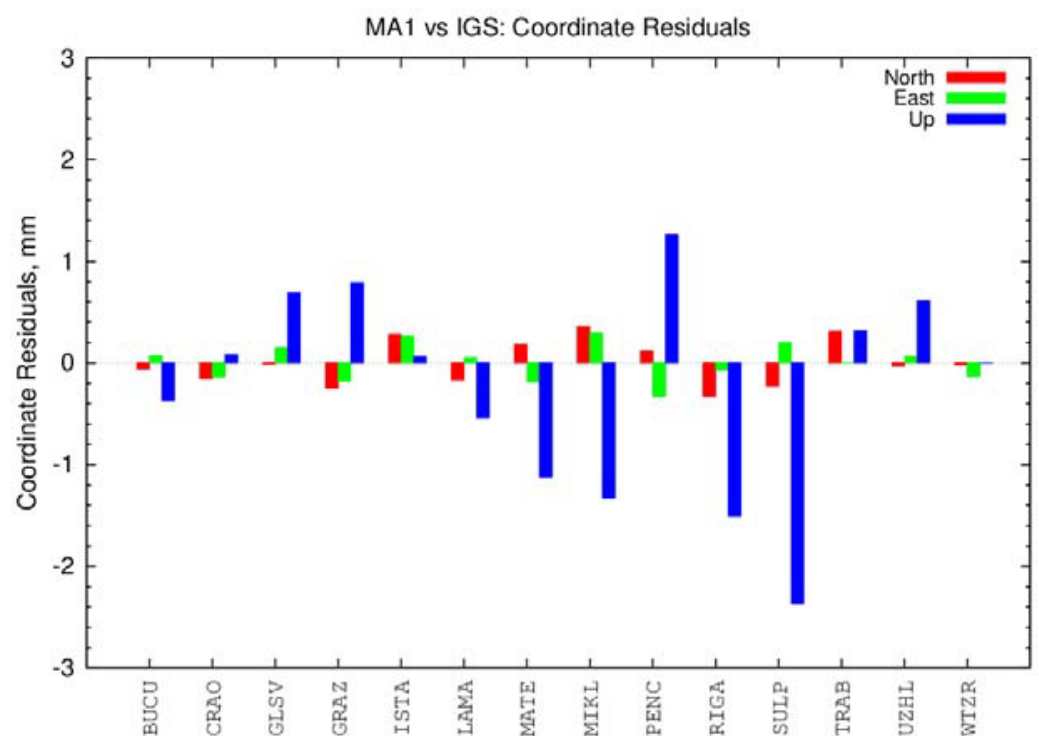

Fig. 5. The mean residual values for the coordinates between solutions $M A I$ and $I G B$ after the Helmert transformation

The minimum and maximum mean residuals (absolute values) have the following values: from $0.02 \mathrm{~mm}$ (station WTZR) to $0.36 \mathrm{~mm}$ (station MIKL) for the north component, from $0.00 \mathrm{~mm}$ (station TRAB) to $0.33 \mathrm{~mm}$ (station PENC) for the east component, from $0.00 \mathrm{~mm}$ (station WTZR) to $2.37 \mathrm{~mm}$ (station SULP) for the up component.

The main reasons for the insignificant differences between the solutions are the same as those from section 3, namely: a different geometry of networks and different ways of the coordinate system realization.

\section{THE ESTIMATION OF THE RMS AND CORRELATION COEFFICIENTS BETWEEN MAO REPRO1, EPN REPRO1 AND IGS REPRO1}

The existence of three different solutions makes it possible to obtain the estimation of the outer RMS accuracy of the solutions. The Helmert transformation was used for adduction of MAI and $E U 0$ solutions to the $I G B$-like definition, because each solution has its own coordinate realization. It was possible to eliminate systematic errors between the solutions by performing this transformation. Large mutual correlations exist between them as all three solutions are based on the same GPS observations. The method, developed in the MAO NAS of Ukraine, was used to estimate the outer errors and correlation coefficients. The idea of the method is as follows. Suppose we have $M$ solution of $N$ common stations. Assuming one of the coordinates $(X, Y$ or $Z$ ) as $x$, for $i$ station we find the values $x_{i}^{o}$ and the error values $\sigma_{i}^{o}$ :

$$
x_{i}^{o}=\frac{\sum_{j=1}^{M} p_{i}^{(j)} x_{i}^{(j)}}{\sum_{j=1}^{M} p_{i}^{(j)}}, \quad\left(\sigma_{i}^{o}\right)^{2}=\frac{1}{\sum_{j=1}^{M} p_{i}^{(j)}},
$$

where $p_{i}^{(j)}=\sqrt{p_{j}^{(j)}}$ - weight coordinates for station $i$ and solution $j$, i.e., $x_{i}^{j}$. We find a common station coordinate differences $\Delta x_{i}^{j o}=x_{i}^{j}-x_{i}^{o}$ and consider the obtained value 
$\left\{\Delta x_{i}^{j o}\right\}_{i=1, \ldots, N}$ as random. We use the centered values and determine the expected value squared differences of coordinates in $l$ and $k$ solutions:

$$
d_{k l}=M\left[\left(\Delta \hat{x}^{k o}-\Delta \hat{x}^{l o}\right)^{2}\right]=\sigma_{k}^{2}+\sigma_{l}^{2}-\rho_{k l} \sigma_{k} \sigma_{l}
$$

where $M[\cdot]$ - operator of the mathematical expectation;

$\sigma_{k}$ and $\sigma_{l}$ - outer mean square error of determining the coordinates in $l$ and $k$ solutions;

$\rho_{k l}$ - correlation coefficient between the corresponding coordinates in $l$ and $k$ solutions;

$\Delta \hat{x}^{k o}-$ are centered values of $\Delta \hat{x}_{i}^{k o}$.

A system of equations calculated with mathematical expectations of sums of squares and differences of coordinates $l$ and $k$ solutions is considered:

$$
\begin{aligned}
& s_{k l}=M\left[\left(\Delta \hat{x}^{k o}+\Delta \hat{x}^{l o}\right)^{2}\right]=\sigma_{k}^{2}+\sigma_{l}^{2}+\rho_{k l} \sigma_{k} \sigma_{l} \\
& d_{k l}=M\left[\left(\Delta \hat{x}^{k o}-\Delta \hat{x}^{l o}\right)^{2}\right]=\sigma_{k}^{2}+\sigma_{l}^{2}-\rho_{k l} \sigma_{k} \sigma_{l}
\end{aligned}
$$

In the case of three solutions, by creating the sum $d_{k l}$ and $s_{k l}$ values, we will obtain a linear system of equations $\sigma_{k}^{2}, \quad k=1,2,3$. Whose solution follows as:

$$
\begin{aligned}
\sigma_{1}^{2} & =\frac{1}{4}\left(s_{12}+s_{13}-s_{23}+d_{12}+d_{13}-d_{23}\right), \\
\sigma_{2}^{2} & =\frac{1}{4}\left(s_{12}+s_{23}-s_{13}+d_{12}+d_{23}-d_{13}\right), \\
\sigma_{3}^{2} & =\frac{1}{4}\left(s_{23}+s_{13}-s_{12}+d_{23}+d_{13}-d_{12}\right) .
\end{aligned}
$$

By creating differences of variables $d_{k l}$ and $s_{k l}$, we can obtain expressions for the correlation coefficients:

$$
\begin{gathered}
\rho_{12}=\frac{s_{12}-d_{12}}{4 \sigma_{1} \sigma_{2}} \\
\rho_{13}=\frac{s_{13}-d_{13}}{4 \sigma_{1} \sigma_{3}} \\
\rho_{23}=\frac{s_{23}-d_{23}}{4 \sigma_{2} \sigma_{3}}
\end{gathered}
$$

Fig. 6 shows the outer mean square errors for the coordinate components $X, Y$ and $Z$ for solutions $M A 1, E U 0$ and $I G B$ for each GPS week. 


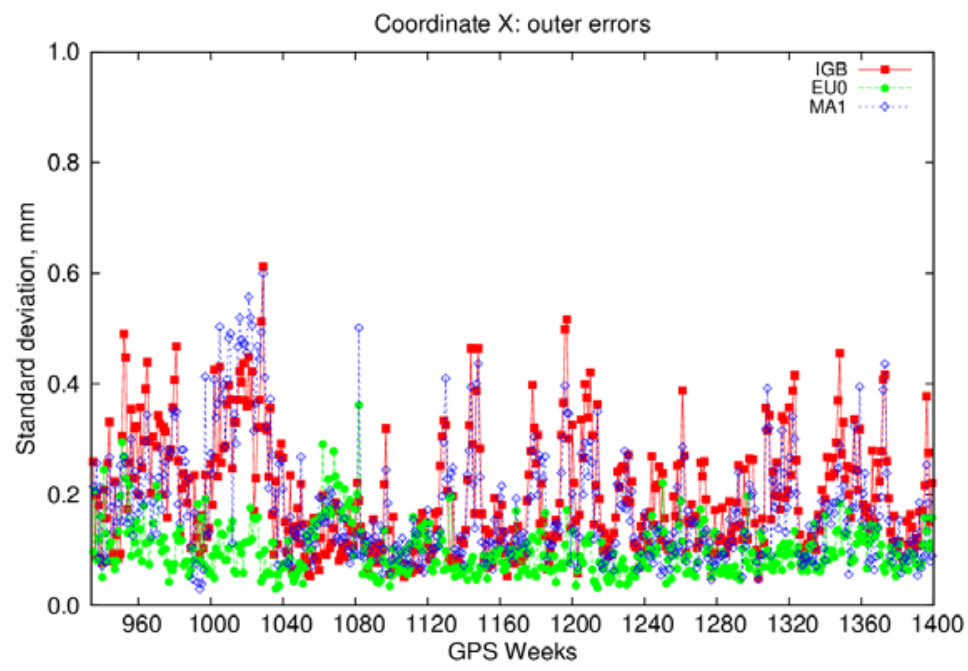

a

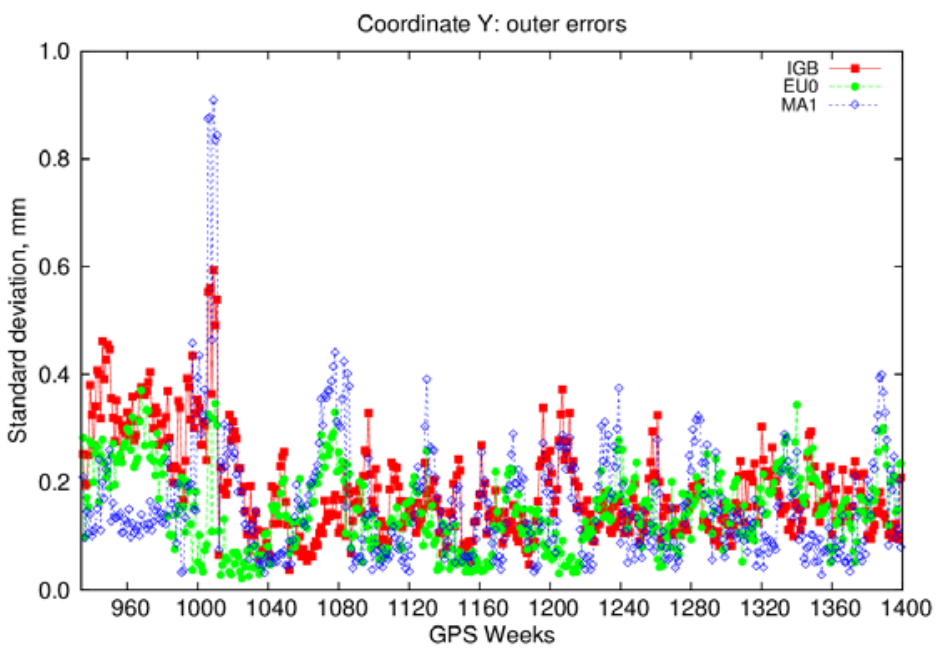

b

Fig. 6 (parts a and b). The value of outer RMS errors for solutions $M A 1, E U 0$ and $I G B$ (a coordinate $X, \mathrm{~b}$ - coordinate $Y, \mathrm{c}$ - coordinate $Z$ ) 


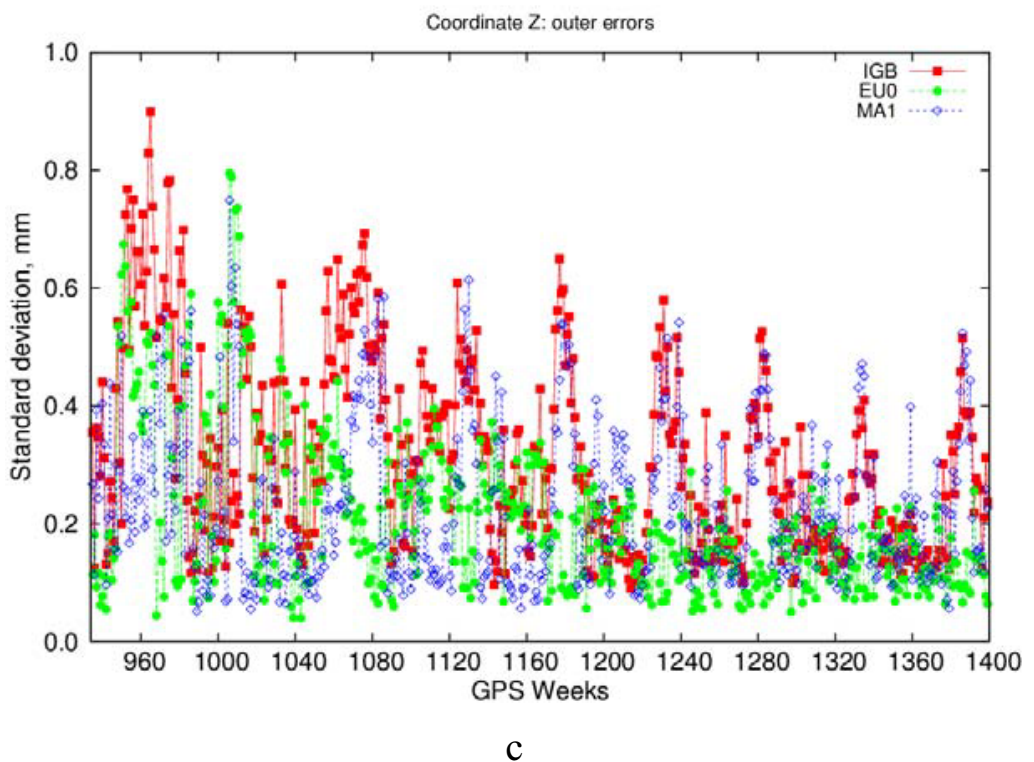

Fig. 6 (part c). The value of outer RMS errors for solutions $M A 1, E U 0$ and $I G B$ (a - coordinate $X, \mathrm{~b}$ - coordinate $Y, \mathrm{c}$ - coordinate $Z$ )

Mean values of the estimated outer RMS errors and correlation coefficients of solutions $M A 1$, $E U O$ and $I G B$ are given in the table 2.

Table. 2. Outer evaluation of the compatibility of the solutions: the mean error values and correlation coefficients

\begin{tabular}{|l|l|l|l|l|l|l|}
\hline Coordinates & $\boldsymbol{\sigma} M A 1, \mathrm{~mm}$ & $\boldsymbol{\sigma} E U 0, \mathrm{~mm}$ & $\boldsymbol{\sigma} I G B, \mathrm{~mm}$ & $\boldsymbol{\rho} E U 0-M A 1$ & $\boldsymbol{\rho} I G B-M A 1$ & $\boldsymbol{\rho} I G B-E U 0$ \\
\hline$X$ & 1,7 & 1,0 & 1,9 & $+0,067$ & $-0,774$ & $-0,418$ \\
\hline$Y$ & 1,6 & 1,5 & 1,8 & $-0,111$ & $-0,610$ & $-0,511$ \\
\hline$Z$ & 2,3 & 2,0 & 3,1 & $+0,053$ & $-0,659$ & $-0,603$ \\
\hline
\end{tabular}

Relatively large values of the correlations between the solutions $I G B-M A I$ and $I G B-E U 0$ may be explained by a different location of GPS stations and a different global coverage of the networks, namely $I G B$ is a global network, $E U O$ - regional, and $M A 1$ - local one, accordingly. However, commonly the solution $M A 1$ shows a similar quality as compared to the $E U D$ and $I G B$ solutions, because the mean error differences are at a level of just a few millimeters.

\section{CONCLUSIONS}

The reprocessing for GPS weeks 935-1399 was carried out using the software package Bernese GPS Software ver. 5.0 at the GNSS Data Center Analysis of the Main Astronomical Observatory (MAO) NAS of Ukraine. Homogeneous coordinate time series in the coordinate system IGS05 and tropospheric zenith path delay parameters for 31 GPS stations in Eastern Europe were obtained.

To check the quality of the solution MAO (MA1) Helmert transformation parameters between the solution $M A 1$ and the combined solutions of International GNSS Service $(I G B)$ and European Permanent GNSS Network (EUO) were obtained. The main differences are caused by distinctions in the network geometry and reference stations different set. The mean values of the zenith 
tropospheric refraction differences between solutions $M A 1$ and EUO lie within the limits (from $0.95 \mathrm{~mm}$ for DEVA, Deva, Romania to $1.05 \mathrm{~mm}$ for COST, Constanta, Romania).

The mean values of the coordinate repeatability for $M A 1$ and EUO solutionsare $0.8 \mathrm{~mm}, 0.7$ $\mathrm{mm}$, and $2.2 \mathrm{~mm}$ for the north, east, and up components, respectively.The RMS values of station coordinate repeatability from a direct comparison between the solutions amount to: for MA1 $1.7 \mathrm{~mm}, 1.6 \mathrm{~mm}$ and $2.3 \mathrm{~mm}$; for EUO - $1.0 \mathrm{~mm}, 1.5 \mathrm{~mm}$ and $2.0 \mathrm{~mm}$; for $I G B-1.9 \mathrm{~mm}, 1.8$ $\mathrm{mm}$ and $3.1 \mathrm{~mm}$ for the $\mathrm{X}, \mathrm{Y}$ and $\mathrm{Z}$ coordinate components, respectively.

The obtained results allow concluding that the solution MAO corresponds to the quality of the reprocessed EPN and IGS solutions.

\section{REFERENCES}

1. Dach R., Hugentobler U., Fridez P., Meindl M. (2007) Bernese GPS Software version 5.0, Astronomical Institute, University of Bern.

2. Ishchenko M. (2012) GPS reprocessing campaign in the Main Astronomical Observatory of NAS Ukraine Abstracts 19-th Open Young Scientists' Conference on Astronomy and Space Physics 2012, Kiev 2012, 56.

3. Guidelines for EPN Analysis Centers, http://www.epncb.oma.be/_organisation/guidelines/guidelines_analysis_centres.php

4. Lyard F. (2006) Modeling the global ocean tides: a modern insight from FES2004, Ocean Dynamics No. 56., 394-415.

5. McCarthy D., Petit G. (2004) IERS Conventions, IERS Technical Note 32, Bundesamt fur Kartographie und Geodëasie, Franfkurt am Main.

6. Niell A. (1996) Global mapping functions for the atmosphere delay at radio wavelenghts // Journal of Geophysical Research, No. 101, 3227-3246.

7. Saastamoinen J. (1972) Atmospheric correction for the troposphere and stratosphere in radio ranging of satellites, The use of artificial satellites for Geodesy, of Geophysics Monogram Series Vol. 15, AGU, 244-251.

8. Standish E. (1990) The Observational basis for JPL's DE200, the planetary ephemerides of the astronomical almanac, Astronomy and Astrophysics, No. 233(1), 252-271.

9. Steigenberg P, Hugentobler U. (2011) CODE contribution to the first IGS Reprocessing campaign, Technical Report, Vol. 1.

10. Steigenberg P., Rothacher M., Fritsche M., Rulke A., Dietrich R. (2009) Quality of reprocessed GPS satellite orbits, Journal of Geodesy, Vol. 83, No. 3-4, 241-248.

11. Vöelksen C. (2011) An update on the EPN Reprocessing Project: current achievements and status, Project EUREF Symposium, http://www.euref.eu/symposia/2011Chisinau/01-06-pVoelksen.pdf

12. Völksen C. (2008) Reprocessing of a regional GPS network in Europe, International of Geodesy Symposium, Springer, Vol. 133, 57-74. 


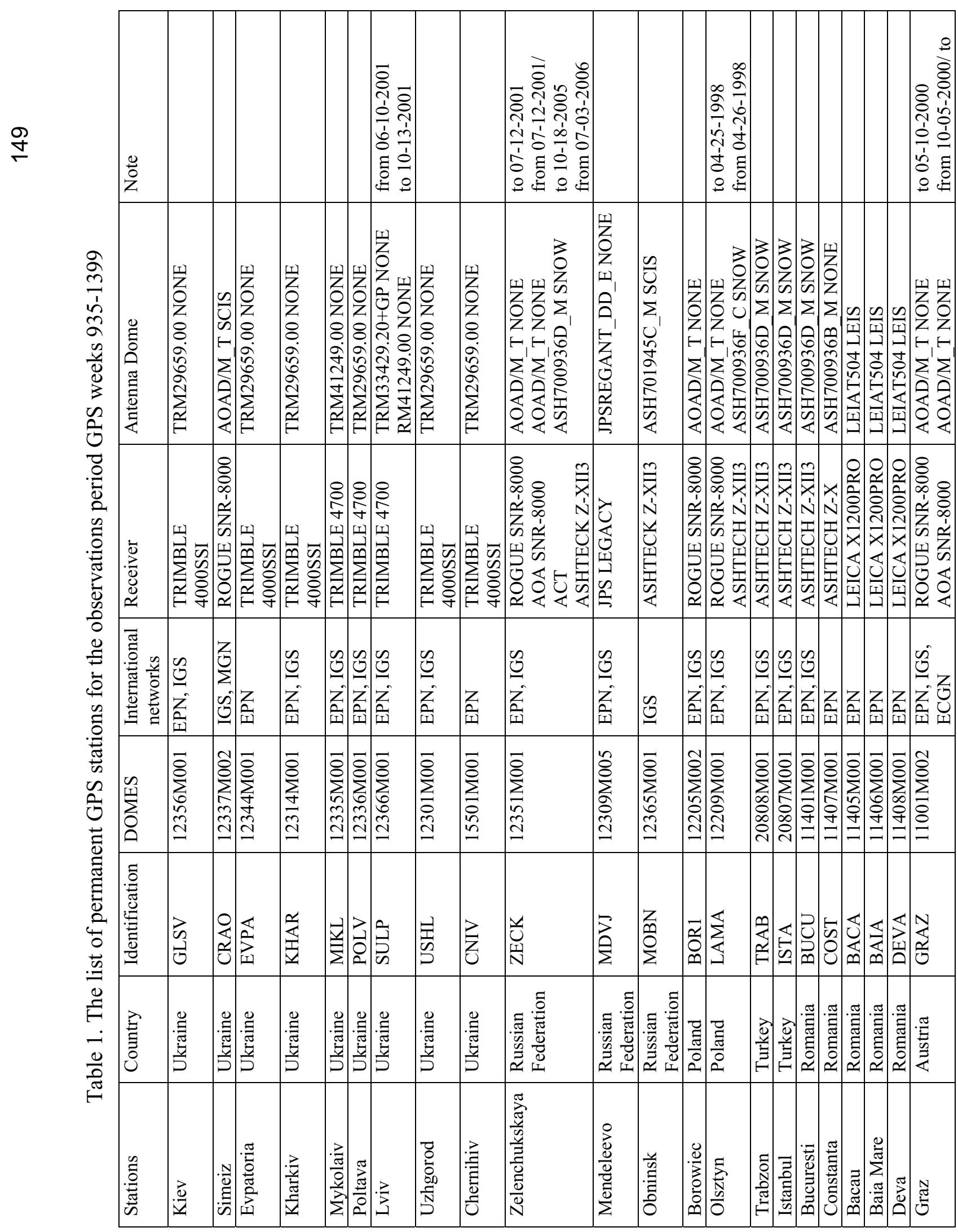




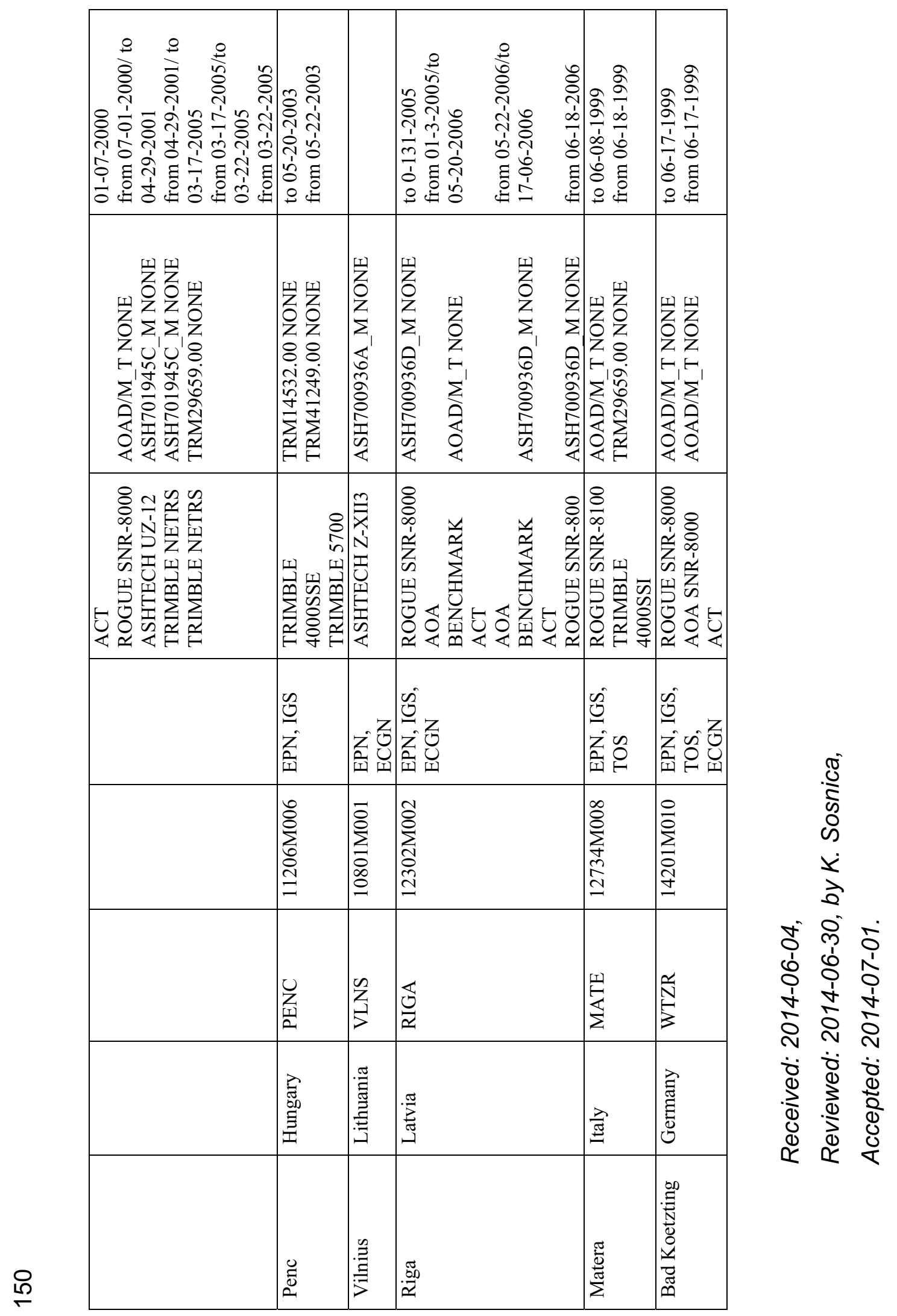

